\title{
Development of a porous titanium-base biomaterial with modulus of elasticity close to that of bone structure
}

\author{
Katia Rivera ${ }^{1}$, Claudia López ${ }^{2}$, Raúl Pérez ${ }^{3}$, D. Lardizabal-Gutiérrez ${ }^{4}$, José Herrera-Ramirez ${ }^{5}$ and C. \\ Carreño-Gallardo ${ }^{6}$
}

${ }^{1}$ CIMAV, Chihuahua, Mexico, ${ }^{2}$ ULSA, Mexico, ${ }^{3}$ COMIMSA, Mexico, ${ }^{4}$ Departamento de Metalurgia e Integridad Estructural, Centro de Investigación en Materiales Avanzados (CIMAV), Avenida Miguel de Cervantes Saavedra 120, Complejo Industrial Chihuahua, 31136 Chihuahua, Chih., Mexico, United States, ${ }^{5}$ Centro de Investigación en Materiales Avanzados (CIMAV), Laboratorio Nacional de Nanotecnología, Miguel de Cervantes 120, 31136 Chihuahua, México, United States, ${ }^{6}$ Centro de Investigación en Materiales Avanzados (CIMAV), Chihuahua, Chihuahua, Mexico

The difference in Young's modulus between an implant device and bone is mainly due to a not homogeneous stress transfer; this is defined as stress shielding. Porous titanium (Ti) with entangled structure has been developed and suggested for potential load-bearing biomedical applications because of its favorable mechanical properties (e.g., good toughness and high reliability in service) and the interconnected porous structure that can provide adequate space for ingrowth of the living tissue [1].

Porous Titanium were produced using a mechanical milling process. The porosity was controlled by adjusting the weight ratio of $\mathrm{Mg}$ to $\mathrm{Ti}$. Titanium hydride-dehydrate powder $(99.5 \%$ purity) with particle sizes of around $44 \mu \mathrm{m}$ and a normally distributed $40-50 \mu \mathrm{m}$ size range was used as the primary matrix. Spherical magnesium powder $(99.8 \%)$ with particle size of around $64 \mu \mathrm{m}$ and normally distributed size range of 55-105 $\mu \mathrm{m}$ was used as the space holder [2].

Titanium and Magnesium powders were mixed in a high energy ball mill without milling media SPEX $8000 \mathrm{M}$ for two hours with weight amounts of magnesium of $15 \%$ and $30 \%$ corresponding to the desired levels of porosity. The powder mixtures were then uniaxially pressed at $530 \mathrm{MPa}$ using a die to obtain cylindrical samples of $6 \mathrm{~mm}$ in diameter and $12 \mathrm{~mm}$ in height for material characterization. Sintering was carried out in a Lindberg high temperature with an argon atmosphere. Samples were sintered at 1000 and $1300{ }^{\circ} \mathrm{C}$ for $2 \mathrm{~h}$. Samples were placed on an Al2O3 ceramic crucible during sintering to prevent contamination. During sintering $\mathrm{Mg}$ powders start to evaporate at $400{ }^{\circ} \mathrm{C}$ [2] and consequently pores form.

The samples fabricated in this work closely match with human cortical bone, biomimetic titanium fabrication using the mechanical milling process with magnesium powder as the space holder material. This process is simple and guaranteed to obtain controlled porosity, the porosity percentage of the sample with $30 \% \mathrm{Mg}$, the porosity percentage was 29.4 and the sample with $15 \% \mathrm{Mg}$ the porosity was $19 \%$.

Figure 1, the specimens with 15 and $30 \% \mathrm{Mg}$ is shown, in a sintered condition at 1000 and $1300{ }^{\circ} \mathrm{C}$. Observing, that at the $1300^{\circ} \mathrm{C}$ condition, a white layer is presented, which is attributed to magnesium oxide.

Figure 2 shows the SEM images of polished cross-sections revealing pore sizes, morphology and distribution. Clearly the magnesium space-holding particles have been removed. 


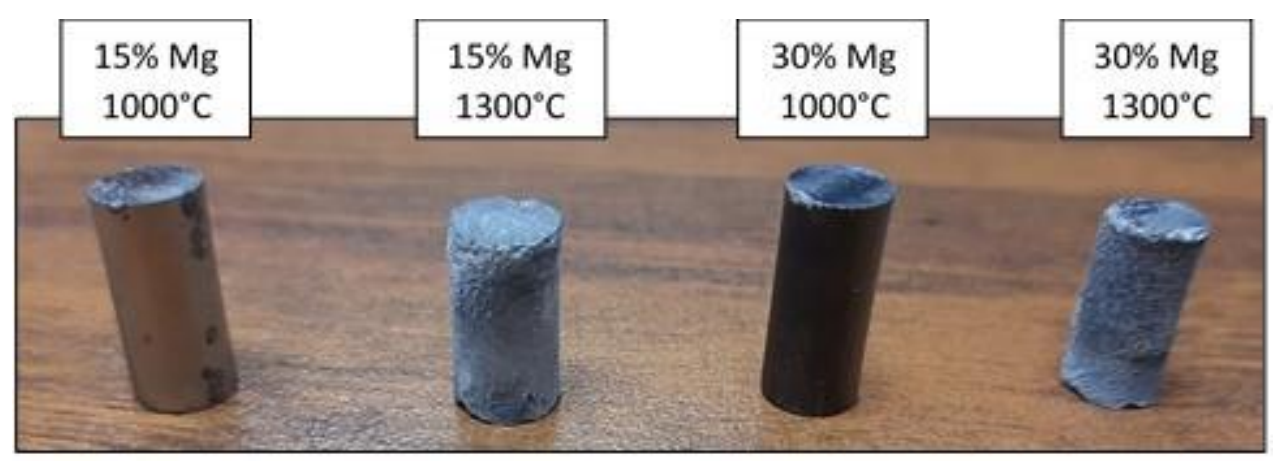

Figure 1. Figure 1. Samples at different sintering temperatures
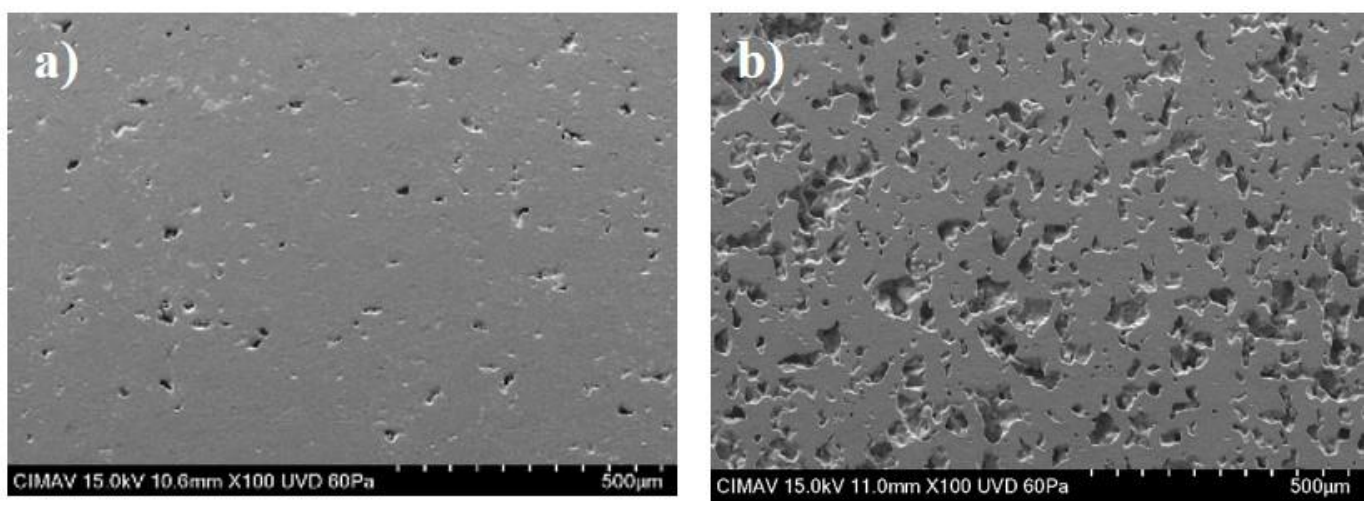

Figure 2. Figure 2. Pore sizes and distribution of the samples $15 \% \mathrm{Mg}$ (a) and $30 \% \mathrm{Mg}(\mathrm{b})$.

\section{References}

[1] Niinomi, Mitsuo \& Nakai, M. (2011). Titanium-Based Biomaterials for Preventing Stress Shielding between Implant Devices and Bone. International journal of biomaterials. 2011. 836587. 10.1155/2011/836587.

[2] Yunhui Chen, Jessica Ellen Frith, Ali Dehghan-Manshadi, Hooyar Attar, Damon Kent, Nicolas Dominique Mathieu Soro, Michael J. Bermingham, Matthew S. Dargusch, Mechanical properties and biocompatibility of porous titanium scaffolds for bone tissue engineering, Journal of the Mechanical Behavior of Biomedical Materials, Volume 75, 2017, Pages 169-174, ISSN 1751-6161, https://doi.org/10.1016/j.jmbbm.2017.07.015.

[3] Skowrouski, S., 1944. By EARL A. GULBRANSEN\$, 534. 589-99. 